\title{
Bilateral Radial Nerve Compression (crutch palsy): A Case Report
}

Ingrid T. Chang* and Anna DePold Hohler

Boston University School of Medicine, 720 Harrison Ave, Suite 707, Boston, MA 02218, USA

\begin{abstract}
Background: Bilateral radial nerve compression due to axillary crutches is a relatively rare entity with few well documented cases in the literature.

Case Report: The purpose of this paper is to present a case of bilateral radial nerve palsy in a man after using axillary crutches for 3 weeks. The axillary crutches were discontinued upon diagnosis; he was started on rehabilitation therapy immediately and showed rapid improvement within days, with full recovery at 5 weeks after presentation.

Conclusion: Crutch palsy occurs from improper use of crutches causing prolonged compression of radial nerve. Proper fitting and education on correct usage of crutches may prevent this complication. A thorough history, physical exam and electrodiagnostic study are helpful in the diagnosis and prognosis of the illness.
\end{abstract}

Keywords: Radial neuropathy; Crutch palsy; Nerve compression syndrome

\section{Introduction}

The radial nerve is also known as the "great extensor nerve" due to its innervation of the triceps, wrist and finger extensors. It originates from the posterior cord of the brachial plexus, and its course along the proximal humerus makes it particularly vulnerable to injury by compression at the proximal arm. In the primary care setting, radial neuropathy is the third most common compressive neuropathy syndrome of the peripheral nerves [1]. "Crutch palsy" occurs when improper use or fitting of crutches causes prolonged compression of the radial nerve at the axilla.

\section{Case}

A 56-year-old male was treated surgically with arthrodesis for avascular necrosis of his left navicular on Nov 11,2010. His surgery was without complications and he was discharged home the same day with a cast in place on his left foot, a set of axillary crutches and instructions on wound care. Three weeks later, he noticed numbness and weakness of his hands and wrist muscles on both sides. Over the next few hours, he noticed gradual difficulty moving his fingers and his wrist, and was unable to hold on to his crutches secondary to his hand and wrist muscle weakness. He presented to the Emergency Department the next day to seek treatment.

The patient's neurologic examination was consistent with bilateral radial nerve palsy with greater involvement on the left side compared to the right. The motor exam was significant for weakness of the triceps (3/5 bilaterally) and bilateral wrist drop (wrist extension was $1 / 5$ on the left, $3 / 5$ on the right). His sensory exam was significant for impaired light touch and pinprick on the lateral forearm extending to dorsum of the hand and first digit bilaterally.

The crutches were immediately discontinued; the patient was treated with gabapentin for sensory disturbances and physical therapy and occupational therapy were started while at the hospital. He showed significant improvement within days after onset of clinical symptoms, with improvement of motor function of triceps (4/5) and wrist extension ( $4 / 5$ bilaterally). Sensory exam was also improved with residual numbness on the lateral forearms bilaterally. One week after initial presentation, he was discharged to subacute physical rehabilitation for further physical and occupational therapy.

At the rehabilitation facility he underwent physical and occupational therapy 5 days/week for 24 days. He was started on rolling walkers in place of the crutches for mobility to prevent further compression of radial nerve at the axilla. His therapy consisted of exercises focusing on upper extremity passive range of motion, active range of motion, active assistive range of motion, fine motor coordination and strengthening exercises.

An EMG performed 5 weeks after initial presentation showed no evidence of radial neuropathy by nerve conduction study or needle exam, and no evidence of bilateral plexopathy bilaterally. At follow up visit 10 weeks after initial presentation, he had full recovery of radial nerve function with his triceps and wrist extension motor function back to baseline bilaterally.

\section{Discussion}

Radial compression neuropathy may be caused by extrinsic or intrinsic compression, and can occur at various locations along the course of the radial nerve. Crutch palsy is a particularly rare form of radial compressive neuropathy [2-5], and occurs when improper use of crutches cause prolonged and excessive compression of the radial nerve at the axilla. Diagnosis of crutch palsy can usually be done clinically by obtaining a detailed history and neurological examination. Improper use of crutches can result in a seven fold increase in the force on the axilla [6]. It is imperative to observe the use of crutches and to ascertain whether the crutches have been fitted properly and whether the patient has been trained on the correct usage of crutches.

*Corresponding author: Ingrid T. Chang, Boston University School of Medicine 720 Harrison Ave, Suite 707, Boston, MA 02218, USA, Tel: (617) 638-8465; Fax: (617) 638-8465; E-mail: ingridtc@bu.edu

Received April 26, 2012; Accepted May 04, 2012; Published May 08, 2012

Citation: Chang IT, DePold Hohler A (2012) Bilateral Radial Nerve Compression (crutch palsy): A Case Report. J Neurol Neurophysiol 3:130. doi:10.4172/21559562.1000130

Copyright: @ 2012 Chang IT, et al. This is an open-access article distributed under the terms of the Creative Commons Attribution License, which permits unrestricted use, distribution, and reproduction in any medium, provided the original author and source are credited. 
On neurologic exam, proximal compression of radial nerve commonly results in weakness in wrist extensors, finger extensors as well as paresthesias in radial nerve distribution $[7,8]$. The mechanism of injury and electrophysiologic findings of crutch palsy is similar to that of acute compressive neuropathies produced by pneumatic tourniquet [5,9]. Ochoa et al. [9] suggested that the critical factor behind development of compressive neuropathy is application of differential pressure along the nerve trunk causing invagination of the nodes of ranvier, rather than nerve ischemia as previously suggested [10]. Electrodiagnostic studies are not necessary for the diagnosis and offer limited value in the first few weeks following nerve injury to prognosticate outcomes $[7,11]$. In a large retrospective study by Rinker et al. [11], 71 out of 79 patients $(90 \%)$ with proximal radial compressive neuropathy had normal findings on electrophysiologic studies. However, some studies suggest that electromyographic studies may help delineate the lesion, and may reveal conduction blocks along the nerves localized to the axilla [5]. Duz et al. [7] has suggested that electrophysiologic studies may be helpful after 12 weeks in assessing which patients are likely to improve and which may eventually require surgery.

In previous well documented cases of axillary compressive neuropathy, most patients had full recovery within 9 weeks, with one case of prolonged recovery period of 9 months after removal of axillary crutches [2-5]. The length of recovery time varied from case to case, and Shyu et al. [8] hypothesized that longer duration of nerve compression may be an indicator of poor prognosis with increased recovery time. In all cases, axillary crutches were discontinued immediately, splints were placed and physical and/or occupational therapy were initiated. These interventions facilitated recovery and prevented stiffness and contractures. None of the patients with crutch palsy in the reported cases [2-5] as well as the patient in our case required surgery. However, if prolonged compression results in weakness and pain that does not improve with several months of splinting, anti-inflammatory agents and rehabilitation therapy, then surgical intervention should be considered to reduce the extent of permanent deficit [12].

In cases of repeated focal pressure neuropathies, one should also consider the diagnosis of hereditary neuropathy with liability to pressure palsies [13] (HNPP). HNPP is a genetic disorder inherited in an autosomal dominant manner. The first attack of pressure palsy usually occurs in the second or third decade. Signs to look for include mild polyneuropathy with or without symptoms, evidence of previous nerve palsy such as focal weakness, atrophy or sensory loss and absent ankle reflexes [13]. Although HNPP is an uncommon cause of neuropathies, a detailed history including family history, neurologic exam and genetic testing may be helpful in identifying the disorder.

In our case, radial nerve was the predominantly affected peripheral nerve based on neurologic exam, and there were no abnormal findings on electromyographic studies performed at 5 weeks after initial diagnosis of radial compressive neuropathy. This is most likely due to rapid recovery following crutch discontinuation and prompt initiation of physical and occupational therapy.

In summary, crutch palsy occurs from improper use of crutches causing prolonged compression of radial nerve. Proper fitting and education on correct usage of crutches may prevent this complication. Crutches should be properly fitted to have the crutch top at 1 to 2 inches below the armpit while the patient is standing upright. The crutch top should have ample cushioning and the patient should be given clear instructions to support themselves with their hand and arm, and to not let the axilla touch the crutch top. A comprehensive history and neurological exam is essential not only for diagnosis but also for prognosis as longer period of nerve compression may be associated with an extended recovery time. Electrodiagnostic studies are not necessary for diagnosis; however they may be helpful in prognosticating outcomes for cases with prolonged recovery period of greater than 12 weeks. Crutch palsy has a fairly good prognosis with complete recovery within several weeks for most cases after discontinuation of axillary crutches and prompt initiation of rehabilitation therapy.

\section{References}

1. Latinovic R, Gulliford MC, Hughes RA (2006) Incidence of common compressive neuropathies in primary care. J Neurol Neurosurg Psychiatry 77: 263-265.

2. Poddar SB, Gitelis S, Heydemann PT, Piasecki P (1993) Bilateral Predominant Radial Nerve Crutch Palsy. A Case Report. Clin Orthop Relat Res 297: 245246 .

3. Raiken S, Froimson MI (1997) Bilateral Brachial Plexus Compressive Neuropathy (Crutch Palsy). J Orthop Trauma 11: 136-138.

4. Rudin LN, Levine L (1951) Bilateral Compression of the Radial Nerve; Crutch Paralysis. Phys Ther Rev 31: 229-231.

5. Subramony SH (1989) Electrophysiological findings in crutch palsy Electromyogr clin Neurophysiol 29: 281-285

6. Ang EJ, Goh JC, Bose K, Toh SL, Choo A (1989) Biofeedback device for patients on axillary crutches. Arch Phys Med Rehabil 70: 644-647.

7. Duz B, Solmaz I, Civelek E, Onal BM, Pusat M, et al. (2010) Analysis of proximal radial nerve injury in the arm. Nueral India 58:230-243.

8. Shyu WC, Lin JC, Chang MK, Tsao WL (1993) Compressive radial nerve palsy induced by military shooting training: clinical and electrophysiological study. $J$ Neurol Neurosurg Psychiatry 56: 890-893.

9. Ochoa J, Fowler TF, Gilliatt RW (1972) Anatomical changes in periphera nerves compressed by a pneumatic tourniquet. J Anat 113: 433-455.

10. Martin FR, Paletta FX (1966) Tourniquet paralysis: a primary vascular phenomenon. South Med J 59: 951-953.

11. Rinker B, Effron CR, Beasley RW (2004) Proximal radial compression neuropathy. Ann Plast Surg 52: 174-180.

12. Eaton CJ, Lister GD (1992) Radial nerve compression. Hand Clin 8: 345-357.

13. Bird TD (2010) Hereditary Neuropathy with Liability to Pressure Palsies. HNPP Hereditary Pressure Sensitive Neuropathy, Tomaculous Neuropathy University of Washington, Seattle. 